\title{
Fully automated predictive intelligent control of oxygenation (PRICO) in resuscitation and ventilation of preterm lambs
}

\author{
Matthias C. Hütten 1,2, Tom G. Goos ${ }^{3,4}$, Daan Ophelders' ${ }^{1}$, Maria Nikiforou' ${ }^{1}$ Elke Kuypers' ${ }^{1}$, Monique Willems ${ }^{5}$, Hendrik J. Niemarkt ${ }^{1}$,
} Jenny Dankelman ${ }^{4}$, Peter Andriessen ${ }^{1,6}$, Thilo Mohns ${ }^{6}$, Irwin K.M. Reiss ${ }^{3}$ and Boris W. Kramer ${ }^{1,5}$

BACKGROUND: Hyperoxia and hypoxia influence morbidity and mortality of preterm infants. Automated closed-loop control of the fraction of inspired oxygen $\left(\mathrm{FiO}_{2}\right)$ has been shown to facilitate oxygen supplementation in the neonatal intensive care unit (NICU), but has not yet been tested during preterm resuscitation. We hypothesized that fully automated $\mathrm{FiO}_{2}$ control based on predefined oxygen saturation $\left(\mathrm{SpO}_{2}\right)$ targets was applicable in both preterm resuscitation and ventilation.

METHODS:Twenty-two preterm lambs were operatively delivered and intubated in a modified EXIT procedure. They were randomized to receive standardized resuscitation with either automated or manual $\mathrm{FiO}_{2}$ control, targeting $\mathrm{SpO}_{2}$ according to the Dawson curve in the first 10 min and $\mathrm{SpO}_{2}$ 90-95\% hereafter. Automated $\mathrm{FiO}_{2}$ control also was applied during surfactant replacement therapy and subsequent ventilation.

RESULTS: Time within target range did not differ significantly between manual and automated $\mathrm{FiO}_{2}$ control during resuscitation, however automated $\mathrm{FiO}_{2}$ control significantly avoided hyperoxia. Automated $\mathrm{FiO}_{2}$ control was feasible during surfactant replacement and kept $\mathrm{SpO}_{2}$ within target range significantly better than manual control during subsequent ventilation.

CONCLUSION: In our model, fully automated $\mathrm{FiO}_{2}$ control was feasible in rapidly changing physiologic conditions during postnatal resuscitation and prevented hyperoxia. We conclude that closed loop $\mathrm{FiO}_{2}$ control is a promising tool for the delivery room.

0 xygen supplementation is one of the most common therapeutic interventions in resuscitation and neonatal intensive care of term and preterm infants (1). However, both hypoxia and hyperoxia must be avoided because of their detrimental effects on morbidity and mortality in these children. While hypoxia may lead to direct and indirect cellular damage, hyperoxia has been associated with oxygen toxicity, oxidative stress (2), and chronic diseases of preterm infants such as bronchopulmonary dysplasia (3) and retinopathy of prematurity (4).

Increase in oxygenation after birth is a gradual process (5). Measurement of oxygen saturation $\left(\mathrm{SpO}_{2}\right)$ by pulse oximetry in the delivery room is feasible in newborn resuscitation (6) and in preterm infants within the first minutes of life (7). $\mathrm{SpO}_{2}$ reference values of preterm infants increase within the first 10 min of life (5). This has led to $\mathrm{SpO}_{2}$ target values incorporated in the current European Resuscitation Council guidelines on resuscitation of newborns (8). In order to avoid hyperoxia, current recommendations advise resuscitation of preterm infants with a mixture of air and oxygen, and to use fraction of inspired oxygen $\left(\mathrm{FiO}_{2}\right)$ between 0.21 and $0.30(9) . \mathrm{FiO}_{2}$ should subsequently be titrated according to $\mathrm{SpO}_{2}(10,11)$. General use of pulse oximetry has been shown to extensively reduce $\mathrm{O}_{2}$-derived toxicity in preterm infants (12). However, keeping $\mathrm{SpO}_{2}$ manually within changing saturation limits during a hectic period of resuscitation is a difficult task. Large deviations from $\mathrm{SpO}_{2}$ targets during resuscitation of preterm infants have been observed in clinical studies (13).

These deviations have also been described during routine NICU care, where $\mathrm{SpO}_{2}$ target ranges are met during $50 \%$ of the time $(14,15)$. Meeting $\mathrm{SpO}_{2}$ targets affects morbidity and mortality, depending on the target range chosen (16-18). Beside overall $\mathrm{SpO}_{2}$ targets, variability of oxygenation influences outcome of preterm infants $(4,19,20)$. A promising solution to optimize oxygen therapy is the employment of an automatic "closed loop" system for regulation of $\mathrm{FiO}_{2}$ based on $\mathrm{SpO}_{2}$. Several clinical trials with different devices have proven feasibility of automated closed loop $\mathrm{FiO}_{2}$ control in the NICU for various modes of ventilation, mixed populations, and by using different algorithms $(14,21-26)$. In addition, an overall reduction of manual interventions during automated control was found in these studies, indicating facilitation of caretakers and nursing staff in clinical routine

\footnotetext{
The first two authors contributed equally to this work.

'Department of Pediatrics, Maastricht University Medical Centre, Faculty of Health, Medicine and Life Sciences, School for Mental Health and Neuroscience, Maastricht, The Netherlands; ${ }^{2}$ Department of Pediatrics, Neonatology, University Clinic Medical Faculty RWTH Aachen, Aachen, Germany; ${ }^{3}$ Department of Pediatrics, Division of Neonatology, Erasmus Medical Centre - Sophia Children's Hospital, Rotterdam, The Netherlands; ${ }^{4}$ Department of Biomechanical Engineering, Delft University of Technology, Delft, The Netherlands; ${ }^{5}$ Department of Pediatrics, Maastricht University Medical Centre, Faculty of Health, Medicine and Life Sciences, School for Oncology and Developmental Biology, Maastricht, The Netherlands; ${ }^{6}$ Department of Pediatrics, Máxima Medical Center, Veldhoven, The Netherlands. Correspondence: Matthias C. Hütten (m.hutten@maastrichtuniversity.nl)
} 


\section{Articles $\mid$ Hütten et al.}

Table 1. Animal characteristics

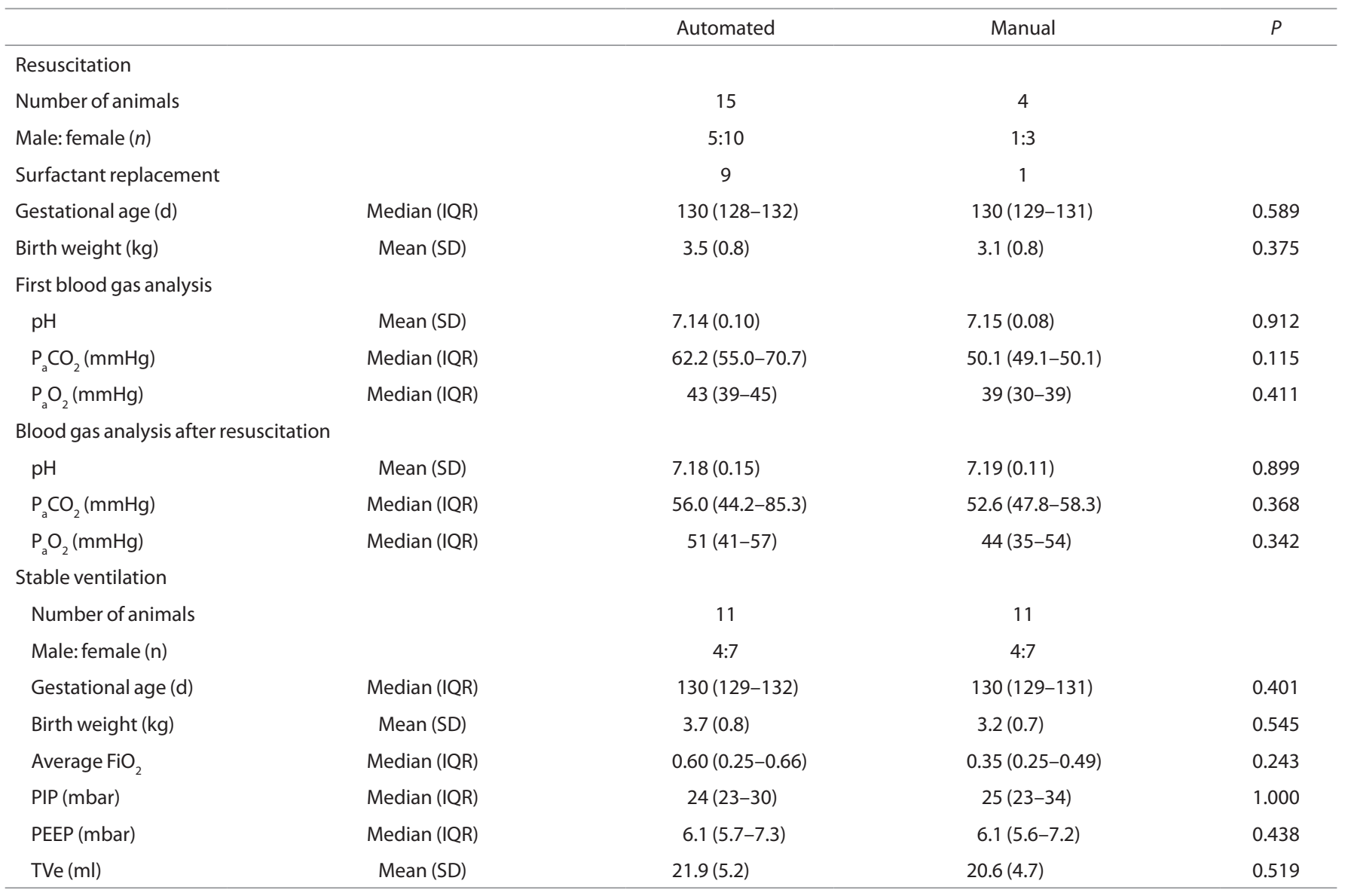

IQR, interquartile range; PIP, positive inspiratory pressure; PEEP, positive end expiratory pressure; TVe, expiratory tidal volume.

$(27,28)$. However, at least one study raised concerns about safety, as time within target range was accompanied by an increase in time spent below saturation target range (25).

The delivery of oxygen is also crucial in the delivery room setting where automated $\mathrm{FiO}_{2}$ control has not yet been tested (28). We therefore hypothesized that an algorithm developed for automated $\mathrm{FiO}_{2}$ control during mechanical ventilation was feasible in the delivery room setting with rapidly changing physiology of fetal transition to extra-uterine life and during surfactant replacement therapy. We further hypothesized that fully automated $\mathrm{FiO}_{2}$ control conducted by this algorithm would keep $\mathrm{SpO}_{2}$ within a predefined target range as good as a dedicated caretaker during stable ventilation conditions. We tested our hypotheses in an established lamb model of preterm respiratory distress syndrome.

\section{RESULTS}

\section{Animal Characteristics}

Preterm lambs did not vary significantly in baseline characteristics and ventilation parameters in both the resuscitation part and the stable ventilation part of the study (Table 1). From 22 animals, 19 animals could be included for analysis of the resuscitation period. 2 animals were excluded because the control software was unintentionally activated other than intended in the protocol, and one animal was excluded because of sensor malfunction. In all animals included, time until first $\mathrm{SpO}_{2}$ measurement was about 2 min (median $106 \mathrm{~s}$, interquartile range (IQR) (80-148 s)) and time until pulse readout of the pulse oximeter correlated to the heart rate was $3 \mathrm{~min}$ on average (median $181 \mathrm{~s}$, IQR (129-271 s)). Fifteen animals underwent automated $\mathrm{FiO}_{2}$ control during resuscitation, from which 9 started with a $\mathrm{FiO}_{2}$ of 0.3 and 6 started with a $\mathrm{FiO}_{2}$ of 0.6 . In four animals $\mathrm{FiO}_{2}$ was controlled manually (starting from $\mathrm{FiO}_{2}$ 0.3 in 3 and from $\mathrm{FiO}_{2} 0.6$ in 1 animal).

\section{Resuscitation}

$\mathrm{SpO}_{2}$ target during resuscitation was defined as 25th and 75th percentile over time for both groups (Figure 1a). Relative time within target range did not differ significantly within groups (Table 2). However, we observed significantly less time spent above the target range in the automated group, while time below the target range was similar (Table 2).

Average time until first $\mathrm{FiO}_{2}$ adjustment was below $3 \mathrm{~min}$ in both the automated and the manual group (median $160 \mathrm{~s}$, IQR (134-208 s) vs. 149 s (81-1698 s), $P=0.317)$. The average number of adjustments during resuscitation was similar in both groups (median 27, IQR (17-35) vs. 28 (20-36); $P=0.796)$. 
a

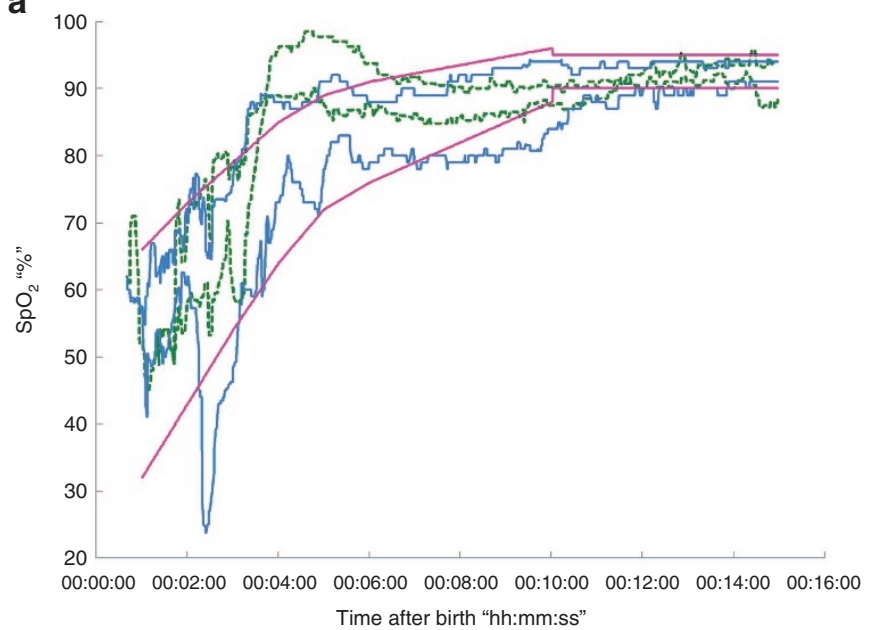

b

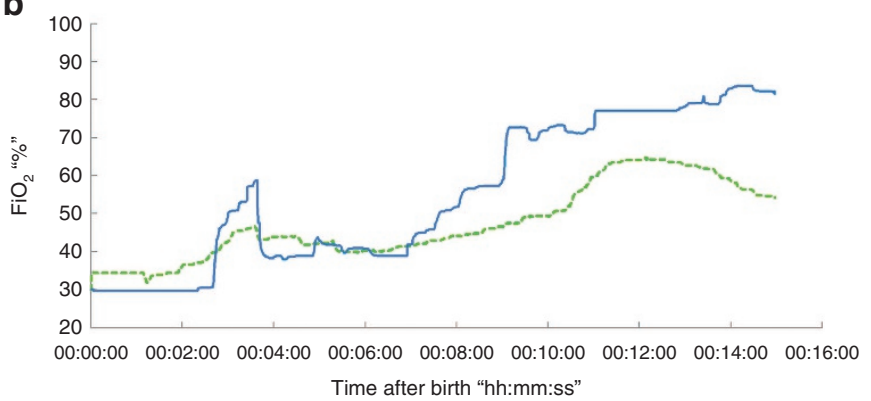

Figure 1. Resuscitation $\mathrm{SpO}_{2}$ and $\mathrm{FiO}_{2}$. (a) $\mathrm{SpO}_{2}$ (\%) during resuscitation is depicted as 25 th and 75 th percentile over time for automated (solid blue line) and manual (dotted green line) $\mathrm{FiO}_{2}$ control. (b) depicts the $\mathrm{FiO}_{2}$ (median) during resuscitation for automated (solid blue lines) and manual (dotted green lines) control.

Table 2. Time within and outside saturation targets during resuscitation

\begin{tabular}{lccc}
\hline \multicolumn{1}{c}{ Automated } & Manual & $P$ \\
\hline Relative time & & & \\
Within target range & $44.3 \%(30.7-48.1 \%)$ & $41.4 \%(28.6-66.8 \%)$ & 0.456 \\
Outside target range & $34.6 \%(25.3-36.7 \%)$ & $42.2 \%(24.7-58.6 \%)$ & 0.212 \\
Above target range & $6.8 \% *(3.4-16.7 \%)$ & $18.9 \%(10.5-32.4 \%)$ & 0.035 \\
Below target range & $20.3 \%(15.4-31.8 \%)$ & $13.3 \%(7.0-43.3 \%)$ & 0.908 \\
Number of times & & & \\
Outside target range & $5(4-9)$ & $8.5(6-10)$ & 0.480 \\
Above target range & $2(1-4)$ & $3.5(2-7)$ & 0.354 \\
Below target range & $3(2-5)$ & $4.5(3-5)$ & 0.826
\end{tabular}

Data is given as median and (IQR).

${ }^{*} P<0.05$ compared to manual.

\section{Automated Resuscitation With $\mathrm{FiO}_{2} 0.3$ vs. 0.6}

Time within target range did not differ between animals receiving automated $\mathrm{FiO}_{2}$ control with an initial $\mathrm{FiO}_{2}$ of 0.3 compared to $\mathrm{FiO}_{2} 0.6$ (median $44.9 \%$, IQR $(24.2-48.5 \%$ ) vs. $40.6 \%$ (30.5-45.9\%), $P=0.814)$. However, animals resuscitated with an initial $\mathrm{FiO}_{2}$ of 0.3 showed significant less time above target range than animals resuscitated with $\mathrm{FiO}_{2}$ of $0.6(3.7 \%$ $(1.6-8.0 \%)$ vs. $14.9 \%(9.2-23.3 \%), P=0.008)$, while time below a

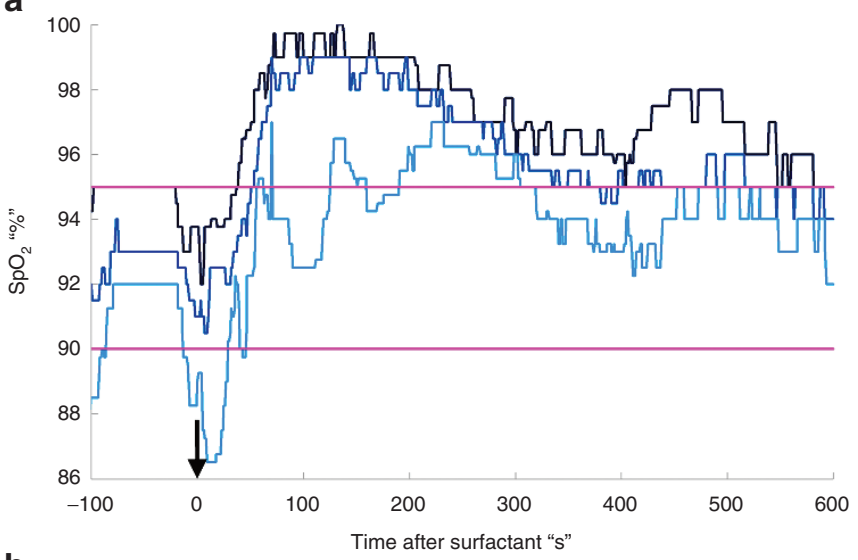

b

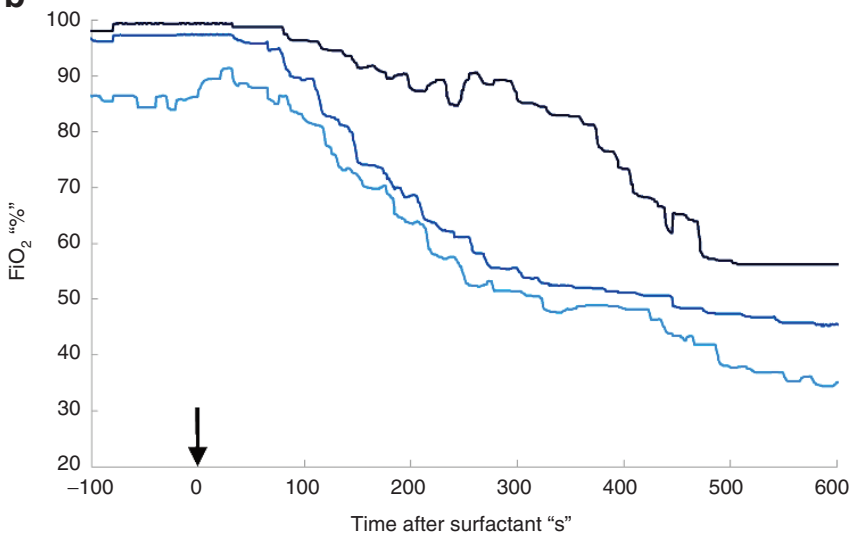

Figure 2. $\mathrm{FiO}_{2}$ and $\mathrm{SpO}_{2}$ after surfactant administration during automated $\mathrm{FiO}_{2}$ control. After surfactant application (arrow), $\mathrm{SpO}_{2}$ (a) reached target range on average within less than $10 \mathrm{~min}$. $\mathrm{FiO}_{2}(\mathbf{b})$ was automatically adjusted according to changed oxygen needs (depicted are median (medium blue), 25th (light blue) and 75th percentile (dark blue line)).

target range did not differ significantly $(23.5 \%(18.9-32.1 \%)$ vs. $19.9 \%(6.4-34.5 \%), P=0.587)$.

Median applied $\mathrm{FiO}_{2}$ at the end of the resuscitation period was higher in the automated group (Figure 1b), however the oxygen need was highly variable in both the automated (IQR $(0.52-0.98))$ and the manual group (IQR (0.37-0.72)).

\section{Automated $\mathrm{FiO}_{2}$ Control During Stabilization and Surfactant Replacement Therapy}

Nine animals received surfactant replacement therapy in the stabilization period during automated $\mathrm{FiO}_{2}$ control. After surfactant replacement, $\mathrm{FiO}_{2}$ was decreased from 0.97 (IQR (0.86$0.99))$ to $0.46(0.35-0.56)$ in $14(10-16)$ steps (Figure 2b). The maximum number of steps the algorithm could make due to timeout restrictions of $30 \mathrm{~s}$ between steps was 20. Average time until the last $\mathrm{FiO}_{2}$ step down after surfactant replacement was $623 \mathrm{~s}$ (IQR 421-807 s).

In the 10 min after surfactant administration $\mathrm{SpO}_{2}$ was subsequently kept close to target ranges, but was within the target range $44 \%$ of the time and above the range 54\% (Figure 2a). Average time until $\mathrm{SpO}_{2}$ was again within target range after surfactant replacement was $576 \mathrm{~s}$ (387-650 s). $\mathrm{SpO}_{2}$, however, reached $100 \%$ in only $9 \%$ of the time. 


\section{Articles $\mid$ Hütten et al.}

a

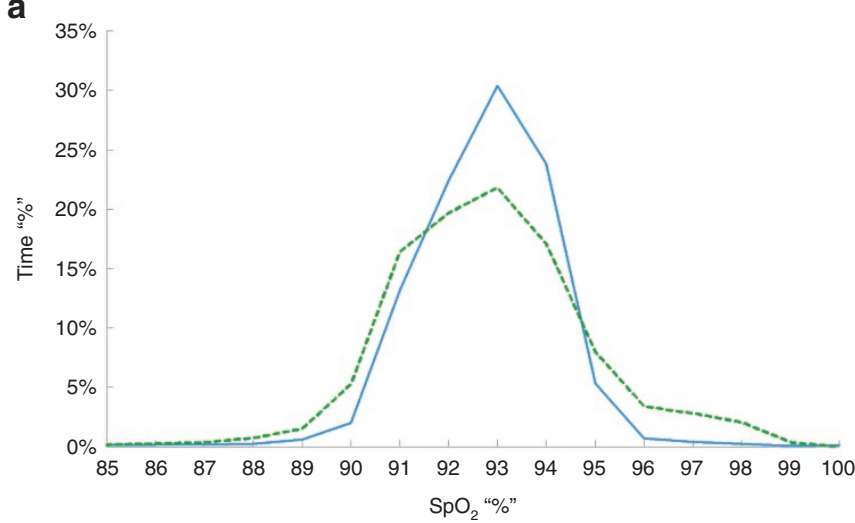

b

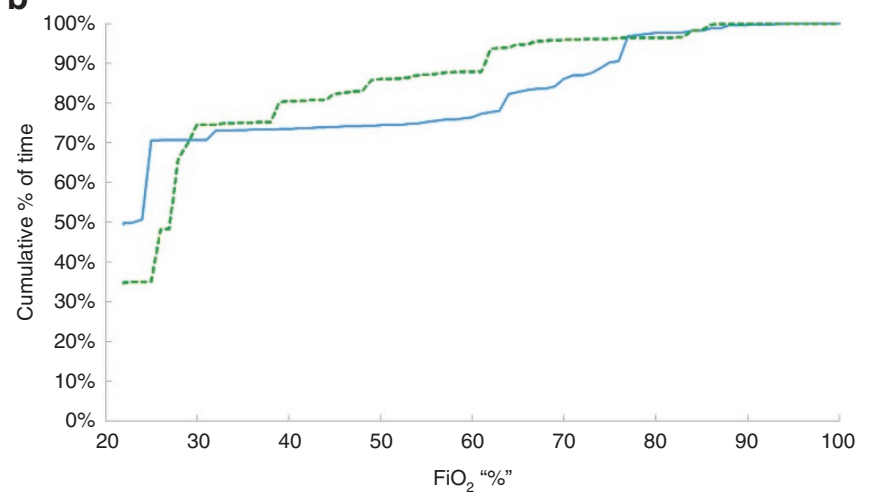

Figure 3. Stable ventilation $\mathrm{SpO}_{2}$ and $\mathrm{FiO}_{2}$. Distribution of oxygen saturation during stable ventilation in percentage of time (a) was significantly more within predefined limits in the automated (solid blue line) compared to the manual (dotted green line) group. Need for supplemental oxygen highly varied between animals in both experimental groups, as depicted (b) by the cumulative percentage of time spent at different levels of $\mathrm{FiO}_{2}$ during stable ventilation in the automated (solid blue line) and manual group (dotted green line).

\section{Stable Ventilation}

Animals were stabilized within the first half hour of life (median 33:11 min:sec, IQR (30:01-39:47 min:sec)). During the subsequent stable ventilation phase, time spend within the target range was significantly higher when the automated controller was used (93.2\% (80.6-98.9\%) vs. 84.0\% (63.8-89.4\%), $P<0.05$, Figure 3a), and time outside the target range, depicted as area under the curve $\left(\mathrm{SpO}_{2}{ }^{*}\right.$ sec per hour) was significantly lower (Figure 3a). The number of episodes outside the target range per hour was also significantly lower in the automated group (Table 3 ).

When comparing hypoxic and hyperoxic episodes, animals ventilated with automated control had significantly less episodes below the lower target saturation of $90 \%$ and showed a trend toward less hyperoxic episodes per hour $(P=0.065$, Table 3). We observed only a small number of short hypoxic $(<85 \%)$ and severe hypoxic $(<75 \%)$ episodes in our model, and number of these episodes did not differ between groups. This was also reflected in the low average deviation of saturation from the median target saturation in both groups (Table 3 ). The duration of hyperoxic, hypoxic and severe hypoxic episodes did no differ significantly between groups.

Compared to manual control, the number of $\mathrm{FiO}_{2}$ adjustments per hour was 2.3 times higher in the automated group,
Table 3. Number and duration of hyperoxic, hypoxic, and severe hypoxic episodes during stable ventilation

\begin{tabular}{lccc}
\hline & Automated & Manual & $P$ \\
\hline $\begin{array}{l}\text { Number of episodes above } \\
\text { 95\% per hour }\end{array}$ & $0.0(0.0-1.4)$ & $3.3(0.6-10.3)$ & 0.065 \\
$\begin{array}{l}\text { Average duration of } \\
\text { episodes }>95 \% \text { (s) }\end{array}$ & $18.5(7.5-51.1)$ & $16.5(13.1-57.7)$ & 0.797 \\
$\begin{array}{l}\text { Number of episodes below } \\
90 \% \text { per hour }\end{array}$ & $1.4^{*}(0.9-2.2)$ & $4.0(1.7-6.4)$ & 0.010 \\
$\begin{array}{l}\text { Average duration of } \\
\text { episodes }<90 \% \text { (s) }\end{array}$ & $4.7(1.0-27.5)$ & $14.6(6.3-49.4)$ & 0.088 \\
$\begin{array}{l}\text { Number of episodes below } \\
85 \% \text { per hour }\end{array}$ & $0.0(0.0-0.3)$ & $0.0(0.0-0.7)$ & 0.748 \\
$\begin{array}{l}\text { Average duration of } \\
\text { episodes }<85 \% \text { (s) }\end{array}$ & $16.5(6.0-29.3)$ & $36.3(6.6-157.5)$ & 0.686 \\
$\begin{array}{l}\text { Number of episodes below } \\
75 \% \text { per hour }\end{array}$ & $0.0(0.0-0.0)$ & $0.0(0.0-0.3)$ & 0,438 \\
$\begin{array}{l}\text { Average duration of } \\
\text { episodes }<75 \% \text { (s) }\end{array}$ & 5.0 & $47.8(1.0-75.0)$ & 1.000 \\
$\begin{array}{l}\text { Average deviation from } \\
\text { target saturation (SpO } \%)\end{array}$ & $1.0(0.0-1.9)$ & $1.7(1.1-2.4)$ & 0.171 \\
\hline $\begin{array}{l}\text { Data is given as median and (IQR). } \\
* P<0.05 \text { compared to manual. }\end{array}$ & & & \\
\hline
\end{tabular}

although this difference was not significant (median 13.0, IQR (3.0-16.4) vs. 5.7 (2.3-9.8), $P=0.243$ ). Applied $\mathrm{FiO}_{2}$ did not differ significantly between groups, and we observed a heterogeneous need for oxygen within the groups (Figure $3 b$ ). Animals in the manual group were outside target range longer with higher oxygen need, however correlation between time outside target range and average $\mathrm{FiO}_{2}$ was not significant $\left(R^{2}\right.$ linear $=0.614, P=0.889$ ). In the automated group, average $\mathrm{FiO}_{2}$ and time outside target range did not correlate $\left(R^{2}\right.$ linear $=0.229, P=0.136$ ).

\section{DISCUSSION}

We tested in our study if fully automated $\mathrm{FiO}_{2}$ control without manual interventions was feasible to keep preterm lambs within a predefined $\mathrm{SpO}_{2}$ target range under both rapidly changing conditions in a delivery room setting and under stable volume guarantee ventilation. Tailoring oxygen supplementation to the needs of preterm infants in the first minutes of life is difficult because of the gradual increase of oxygenation (5). In our study, time within target range with both manual and automated $\mathrm{FiO}_{2}$ control resembled clinical data obtained in the delivery room (13).

Our data indicated that automated $\mathrm{FiO}_{2}$ control avoided hyperoxia during resuscitation. This might have resulted from the algorithm following the target ranges in a stricter way than the human controller, although the number of adjustments and time until first $\mathrm{FiO}_{2}$ adjustment did not differ between groups. However, we did not see significantly more time within target range in automated $\mathrm{FiO}_{2}$ control during resuscitation. A possible explanation is that the caretaker providing manual $\mathrm{FiO}_{2}$ adjustments was able to see the changing $\mathrm{SpO}_{2}$ target ranges depicted as Dawson's curve during resuscitation 


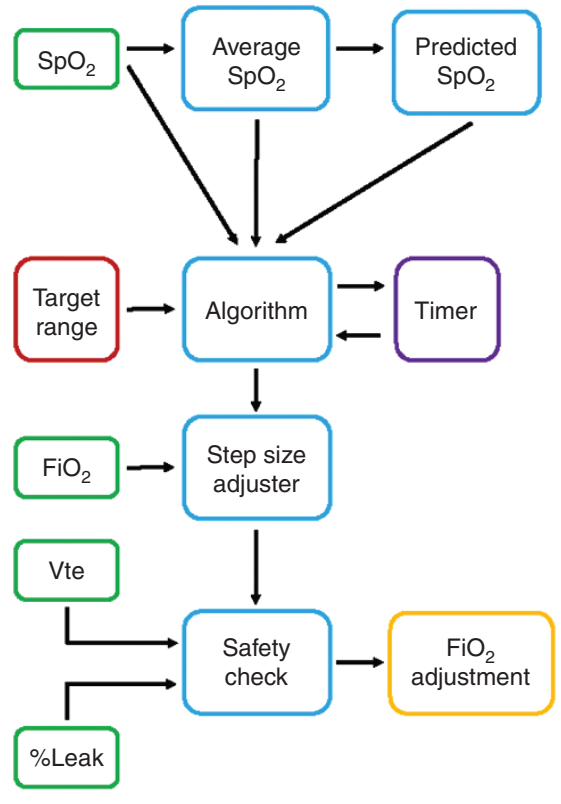

Figure 4. Flow scheme of algorithm.

and therefore had more information about saturation trends than in a standard delivery room. This could have facilitated the decision for which $\mathrm{FiO}_{2}$ to provide, and made it easier to achieve saturations within the limits than during routine clinical resuscitation where $\mathrm{SpO}_{2}$ is presented only by pulse oximeter readout. However, we cannot rule out that the manual adjustments were based on additional clinical parameters such as heart rate, although heart rate increased adequately in both groups. Automated $\mathrm{FiO}_{2}$ control might be further improved by choosing a narrowed target range. By basing the target range on Dawson's curve, the predefined range was broader during resuscitation than during subsequent ventilation. Closed loop $\mathrm{FiO}_{2}$ control has already been shown to maintain functionality in a setting of narrowed target ranges in the NICU (29). Furthermore, automated $\mathrm{FiO}_{2}$ control might be improved by allowing the algorithm to change $\mathrm{FiO}_{2}$ more frequently, although the limitation of at least $30 \mathrm{~s}$ between two steps resembled clinical recommendations (10).

Avoidance of oxygen overexposure is a major concern for implementing automated control in the delivery room (28). In our study, animals resuscitated with an initial $\mathrm{FiO}_{2}$ of 0.3 showed less $\mathrm{SpO}_{2}$ above target range than animals initially resuscitated with $\mathrm{FiO}_{2}$ 0.6, although $\mathrm{FiO}_{2}$ had to be increased during resuscitation in the first group. The starting $\mathrm{FiO}_{2}$ had an effect until about $5 \mathrm{~min}$ after birth. This observation is in accordance to a previous study where initial $\mathrm{FiO}_{2}$ of 0.3 or $0.65 \mathrm{had}$ a significant effect on the $\mathrm{FiO}_{2}$ during the first 6 min of life (30). This data supports previous findings that resuscitation with initially low $\mathrm{FiO}_{2}$ might be beneficial for preterm infants (9).

Automated $\mathrm{FiO}_{2}$ control was also feasible directly after surfactant replacement therapy. The automated controller showed immediate and adequate reaction on the altered needs for supplemental oxygen. In this scenario, a caretaker might have the advantage from knowing what to expect from the applied treatment. However, the small number of animals receiving surfactant during the study did not allow us a direct comparison between automated and manual control after surfactant replacement therapy.

During stable ventilation, animals receiving automated $\mathrm{FiO}_{2}$ control spent significantly more time within the predefined target range. This advanced performance of the controller was striking, as manual control was performed in a 1-on-1 setting by a person without other tasks than ventilation control during the experiment. This dedicated $\mathrm{FiO}_{2}$ control, which is different from the clinical situation, improved time within target range compared to routine control in a previous study (23). In a clinical setting, meeting $\mathrm{SpO}_{2}$ target ranges depends-among others-on patient-caretaker ratio (31). Most closed loop studies compared automated to routine clinical care (14,21,24-26), only one study could show a significant improvement comparing closed loop to dedicated manual control (22). In addition, in our study, alarm range was equal to target range, which created an ideal setting for dedicated manual control as caregivers are more effective in keeping $\mathrm{SpO}_{2}$ within alarm limits then within target limits in preterm infants (32). Interestingly, our data suggest that keeping animals manually within the limits was more difficult with high oxygen need, while individual oxygen need did not influence the performance of the automated control.

We therefore conclude that automated $\mathrm{FiO}_{2}$ control is applicable both during rapidly changing physiologic conditions and during stable ventilation. Automated $\mathrm{FiO}_{2}$ control has therefore the potential to facilitate delivery room management during resuscitation. On the NICU, automated $\mathrm{FiO}_{2}$ control reduced the need for manual interventions during automated control by $33-90 \%$ (23-25). Only one study reported no manual interventions during automated control (22), however the overall time within target range for both manual and automated control was lower and the target range was wider compared to our study. The potential of acting autonomously for at least a certain time is a prerequisite of safe use of automated $\mathrm{FiO}_{2}$ control in this vulnerable patient population.

Nevertheless, automated control cannot outrun clinical experience, as therapeutic interventions in the delivery room have to be adapted to a multitude of parameters (33). Early $\mathrm{SpO}_{2}$ is related not only to $\mathrm{FiO}_{2}$, but also to factors like adequate functional residual capacity (34) and perinatal procedures like delayed cord clamping (35). In addition, rising need for oxygen can be a symptom of a pathological condition such as pneumothorax or of a ventilation-related complication, e.g., tube dislocation. Automated control may mask these changes, at least for a short period of time. Therefore, adequate feedback about automated intervention to the caretaker must be ensured. Additional alarms for parameters like tidal volume (TVe) should be routinely implemented.

Our model is limited by the fact that animals were mildly sedated for mechanical ventilation, partially preventing spontaneous breathing. Hypoventilation after episodes of active breathing during mechanical ventilation has been previously described as important contributor to desaturations 
in ventilated preterm children (36). Automated $\mathrm{FiO}_{2}$ control might be ineffective in prevention of hypoxic spells (27). However, our data suggest that automated control prevented episodes below target and might therefore have an effect on these episodes, as hypoxic spells have been associated with lower average $\mathrm{SpO}_{2}$ levels (37). This highlights the need for additional studies investigating the influence of parameters defining the automated controller.

In summary, to the best of our knowledge, this is the first study where we demonstrate that fully automated $\mathrm{FiO}_{2}$ control is feasible during neonatal resuscitation in a near-clinical preterm delivery room setting, and that automated control prevents hyperoxia. We speculate that in a clinical scenario where not only $\mathrm{SpO}_{2}$ but also clinical evaluation of the patient influence oxygen therapy, the combination of automated and manual control might even imply better results. However, this question may best be addressed in a clinical trial. In parallel, translational trials will help to improve closed-loop equipment.

\section{METHODS}

\section{Experimental Setup}

An infant ventilator (Fabian HFO, Acutronic, Hirzel, Switzerland) was prepared for digital control of the $\mathrm{FiO}_{2} . \mathrm{SpO}_{2}$ measurement was obtained via a Masimo pulse oximeter (Radical 7, Masimo, Irvine, CA). Both devices were linked to a laptop computer (ThinkPad T500, Lenovo Pte., Singapore, with Windows 7, Microsoft, Redmond, WA), containing control software with a user interface showing $\mathrm{SpO}_{2}, \mathrm{FiO}_{2}$, pulse, and $\mathrm{SpO}_{2}$ target ranges over time (as presented by Goos et al. on the 4th Congress of the European Academy of Pediatric Societies 2012). The algorithm used was a rule based control scheme that used both the current $\mathrm{SpO}_{2}$ together with the trend in the $\mathrm{SpO}_{2}$ measurement (Figure 4). The trend was used to fine tune the $\mathrm{FiO}_{2}$ step size by recognizing larger and quicker changes. A prediction based on the trend was used to limit under- and overshoot. A number of safety checks were performed before an automated $\mathrm{FiO}_{2}$ adjustment could be made, i.e. check for proper ventilation (TVe and percentage of leak within acceptable limits), reliable connections between all devices and an assessment of the correctness of all measured parameters. After each adjustment, a $30 \mathrm{~s}$ time out followed to allow the effect of the adjustment to be observed.

\section{Animal Study}

The lamb model of neonatal respiratory distress syndrome allowed us a translational approach due to its physiologic similarities to lung development in humans $(38,39)$. Furthermore, anatomy and body size allowed us the use of the original equipment used in the neonatal intensive care units. The study design and the experimental protocol were in line with the institutional guidelines for animal experiments and were approved by the institutional Animal Ethics Research Committee, Maastricht University, The Netherlands.

One day before cesarean section, 22 date-mated ewes received an intramuscular injection with betamethasone $(12 \mathrm{mg}$, Celestone Chronodose, Schering-Plough, North Ryde, New South Wales, Australia) to induce fetal lung maturation (40). Before delivery, lambs were randomly assigned to four different treatment groups for resuscitation and independently for two different treatment groups for subsequent stable ventilation. This setup allowed us to separately analyze the algorithm during rapidly changing and stable conditions.

\section{Resuscitation}

Lambs were operatively delivered prematurely at a gestational age of 128-132 d (term $\sim 150 \mathrm{~d}$ ) via a modified EXIT procedure, equipped with umbilical artery and vein catheters and intubated orally with a cuffed tube (41). The arterial catheter was used to monitor heart rate and blood pressure, and to frequently obtain blood for blood gas analysis. After cord clamping, lambs were weighed, sedated, and transferred to an infant radiator bed (IW930 Series CosyCot Infant Warmer, Fisher \& Paykel Healthcare, Auckland, New Zealand). An adhesive pulse oximeter sensor (M-LNCS Neo, MasimoSET, Masimo, Irvine, CA) was placed around the tongue and subsequently connected to the pulse oximeter. Resuscitation in the first $15 \mathrm{~min}$ was standardized to the greatest possible extend. This was achieved by connecting lambs to an infant ventilator set to volume-controlled mechanical ventilation (volume guarantee $6-7 \mathrm{ml} / \mathrm{kg}$, max. PIP 45 $\mathrm{cmH}_{2} \mathrm{O}$, frequency $50 / \mathrm{min}$ ). $\mathrm{FiO}_{2}$ at start of resuscitation was randomized to either 0.3 or 0.6 . $\mathrm{FiO}_{2}$ was adjusted to keep the lamb within the 25th and 75th percentile of saturation in preterm infants according to Dawson (5) for the first $10 \mathrm{~min}$ and subsequently between 90 and $95 \%$. In all experiments, $\mathrm{FiO}_{2}$ was either controlled by the algorithm alone, without manual interventions allowed, or by a caretaker. This person was solely dedicated to adjusting $\mathrm{FiO}_{2}$, while resuscitation was performed by others. $\mathrm{FiO}_{2}$ adjustment was performed by experienced animal researchers and medical doctors or last year students with experience in neonatology, who were not limited regarding frequency and size of $\mathrm{FiO} 2$ changes. Outcome parameters for the resuscitation part were time within, above and below target range, number of events outside the target range, and total number of $\mathrm{FiO}_{2}$ adjustments.

\section{Stabilization and Surfactant Replacement Therapy}

Resuscitation was followed by a short stabilization period. Animals which needed a fraction of inspired oxygen $\left(\mathrm{FiO}_{2}\right)$ above 0.8 at any time during resuscitation or stabilization were eligible to receive surfactant replacement therapy with Poractant alfa (Curosurf, $100 \mathrm{mg} / \mathrm{kg}$ body weight, a gift of Chiesi Pharmaceuticals, Pari, Italy). Lambs were considered to be stabilized after $30 \mathrm{~min}$, or if they received surfactant, 15 min after surfactant replacement therapy. We recorded $\mathrm{SpO}_{2}$ and $\mathrm{FiO}_{2}$ before and after surfactant replacement therapy.

\section{Stable Ventilation}

After stabilization, stabilized lambs were mechanically ventilated with either automated or manual $\mathrm{FiO}_{2}$ control for $3 \mathrm{~h}$. Automated $\mathrm{FiO}_{2}$ control was performed without additional manual interventions. In the manual group, caretaker-lamb ratio was 1:1. Arterial blood gas analysis was obtained every $30 \mathrm{~min}$ and respiratory settings were adjusted to keep $\mathrm{P}_{2} \mathrm{CO}_{2}$ between 45 and $65 \mathrm{mmHg}$. Saturation target range was $90-95 \%$ according to current consensus guidelines from European neonatologists (42), and the alarm range was set accordingly. Outcome parameters were time within and outside $\mathrm{SpO}_{2}$ target range (90-95\%), number and duration of episodes of hyperoxia $\left(\mathrm{SpO}_{2}\right.$ $>95 \%)$, hypoxia $(<85 \%)$ and severe hypoxia $(<75 \%)$, average variation from median target saturation and total number of $\mathrm{FiO}_{2}$ adjustments. For analysis, we excluded times when (i) animals showed saturation above the high target without a need for supplemental oxygen or when (ii) $\mathrm{SpO}_{2}$ was below the low target despite $\mathrm{FiO}_{2}$ of 1.0. This was done because during these episodes, $\mathrm{FiO}_{2}$ control alone was not capable of keeping oxygen targets within the predefined limits.

\section{Statistics}

Normally distributed data are expressed as mean and SD, non-normally-distributed data are expressed as median and IQR. Statistical analysis was performed using Student's $t$-test for normally distributed data and Mann-Whitney test for non-normally distributed data, using IBM SPSS version 20 (IBM, Armink, NY). Graphs were drawn with Microsoft Excel 2010 and GraphPad Prism v5.0 (GraphPad Software, San Diego, CA). Significance was accepted at $\mathrm{p}<0.05$.

\section{STATEMENT OF FINANCIAL SUPPORT}

The study was sponsored by Acutronic, Hirzel, Switzerland, who also provided us with technical equipment, but did not influence study design, did not participate in the collection, analysis, and interpretation of data and writing of the report, and did not decide on submission of the paper for publication. The authors declare no additional conflict of interest.

\section{REFERENCES}

1. Finer N, Rich W. Neonatal resuscitation for the preterm infant: evidence versus practice. J Perinatol 2010;30 Suppl:S57-66.

2. Saugstad OD. Update on oxygen radical disease in neonatology. Curr Opin Obstet Gynecol 2001;13:147-53. 


\section{Automated oxygen control after birth}

3. Laughon M, Allred EN, Bose C, et al.; ELGAN Study Investigators. Patterns of respiratory disease during the first 2 postnatal weeks in extremely premature infants. Pediatrics 2009;123:1124-31.

4. Cunningham S, Fleck BW, Elton RA, McIntosh N. Transcutaneous oxygen levels in retinopathy of prematurity. Lancet 1995;346:1464-5.

5. Dawson JA, Kamlin CO, Vento M, et al. Defining the reference range for oxygen saturation for infants after birth. Pediatrics 2010;125:e1340-7.

6. Sendak MJ, Harris AP, Donham RT. Use of pulse oximetry to assess arterial oxygen saturation during newborn resuscitation. Crit Care Med 1986;14:739-40.

7. Maxwell LG, Harris AP, Sendak MJ, Donham RT. Monitoring the resuscitation of preterm infants in the delivery room using pulse oximetry. Clin Pediatr (Phila) 1987;26:18-20.

8. Richmond S, Wyllie J. European Resuscitation Council Guidelines for Resuscitation 2010 Section 7. Resuscitation of babies at birth. Resuscitation 2010;81:1389-99.

9. Saugstad OD, Aune D, Aguar M, Kapadia V, Finer N, Vento M. Systematic review and meta-analysis of optimal initial fraction of oxygen levels in the delivery room at $\leq 32$ weeks. Acta Paediatr 2014;103:744-51.

10. Vento M, Aguar M, Brugada M, et al. Oxygen saturation targets for preterm infants in the delivery room. J Matern Fetal Neonatal Med 2012;25 Suppl 1:45-6.

11. Vento M. Oxygen supplementation in the neonatal period: changing the paradigm. Neonatology 2014;105:323-31.

12. Finer N, Leone T. Oxygen saturation monitoring for the preterm infant: the evidence basis for current practice. Pediatr Res 2009;65:375-80.

13. Goos TG, Rook D, van der Eijk AC, et al. Observing the resuscitation of very preterm infants: are we able to follow the oxygen saturation targets? Resuscitation 2013;84:1108-13.

14. Bhutani VK, Taube JC, Antunes MJ, Delivoria-Papadopoulos M. Adaptive control of inspired oxygen delivery to the neonate. Pediatr Pulmonol 1992;14:110-7.

15. van der Eijk AC, Dankelman J, Schutte S, Simonsz HJ, Smit BJ. An observational study to quantify manual adjustments of the inspired oxygen fraction in extremely low birth weight infants. Acta Paediatr 2012;101: e97-104.

16. Carlo WA, Finer NN, Walsh MC, et al. Target ranges of oxygen saturation in extremely preterm infants. N Engl J Med 2010;362:1959-1969.

17. Askie LM, Brocklehurst P, Darlow BA, Finer N, Schmidt B, TarnowMordi W; NeOProM Collaborative Group. NeOProM: Neonatal Oxygenation Prospective Meta-analysis Collaboration study protocol. BMC Pediatr 2011;11:6.

18. Schmidt B, Whyte RK, Asztalos EV, et al.; Canadian Oxygen Trial (COT) Group. Effects of targeting higher vs lower arterial oxygen saturations on death or disability in extremely preterm infants: a randomized clinical trial. JAMA 2013;309:2111-20.

19. Di Fiore JM, Bloom JN, Orge F, et al. A higher incidence of intermittent hypoxemic episodes is associated with severe retinopathy of prematurity. J Pediatr 2010;157:69-73.

20. Martin RJ, Wang K, Köroğlu O, Di Fiore J, Kc P. Intermittent hypoxic episodes in preterm infants: do they matter? Neonatology 2011;100:303-10.

21. Morozoff PE, Evans RW. Closed-loop control of $\mathrm{SaO} 2$ in the neonate. Biomed Instrum Technol 1992;26:117-23.

22. Claure N, Gerhardt T, Everett R, Musante G, Herrera C, Bancalari E. Closed-loop controlled inspired oxygen concentration for mechanically ventilated very low birth weight infants with frequent episodes of hypoxemia. Pediatrics 2001;107:1120-4.

23. Urschitz MS, Horn W, Seyfang A, et al. Automatic control of the inspired oxygen fraction in preterm infants: a randomized crossover trial. Am J Respir Crit Care Med 2004;170:1095-100.
24. Morozoff EP, Smyth JA. Evaluation of three automatic oxygen therapy control algorithms on ventilated low birth weight neonates. Conf Proc IEEE Eng Med Biol Soc 2009;2009:3079-82.

25. Claure N, Bancalari E, D'Ugard C, et al. Multicenter crossover study of automated control of inspired oxygen in ventilated preterm infants. Pediatrics 2011;127:e76-83.

26. Hallenberger A, Poets CF, Horn W, Seyfang A, Urschitz MS; CLAC Study Group. Closed-loop automatic oxygen control (CLAC) in preterm infants: a randomized controlled trial. Pediatrics 2014;133:e379-85.

27. Claure N, Bancalari E. Automated closed loop control of inspired oxygen concentration. Respir Care 2013;58:151-61.

28. Hummler H, Fuchs H, Schmid M. Automated adjustments of inspired fraction of oxygen to avoid hypoxemia and hyperoxemia in neonates - a systematic review on clinical studies. Klin Padiatr 2014; 226:204-10.

29. Wilinska M, Bachman T, Swietlinski J, Kostro M, Twardoch-Drozd M. Automated $\mathrm{FiO} 2-\mathrm{SpO} 2$ control system in neonates requiring respiratory support: a comparison of a standard to a narrow $\mathrm{SpO} 2$ control range. $\mathrm{BMC}$ Pediatr 2014;14:130.

30. Rook D, Schierbeek H, Vento M, et al. Resuscitation of preterm infants with different inspired oxygen fractions. J Pediatr 2014;164:1322-6.e3.

31. Sink DW, Hope SA, Hagadorn JI. Nurse:patient ratio and achievement of oxygen saturation goals in premature infants. Arch Dis Child Fetal Neonatal Ed 2011;96:F93-8.

32. Hagadorn JI, Furey AM, Nghiem TH, et al.; AVIOx Study Group. Achieved versus intended pulse oximeter saturation in infants born less than 28 weeks' gestation: the AVIOx study. Pediatrics 2006;118: 1574-82.

33. Rich WD, Leone T, Finer NN. Delivery room intervention: improving the outcome. Clin Perinatol 2010;37:189-202.

34. Hooper SB, Harding R. Role of aeration in the physiological adaptation of the lung to air-breathing at birth. Curr Resp Med Rev 2005;2: 185-195.

35. Valero J, Desantes D, Perales-Puchalt A, Rubio J, Diago Almela VJ, Perales A. Effect of delayed umbilical cord clamping on blood gas analysis. Eur J Obstet Gynecol Reprod Biol 2012;162:21-3.

36. Bolivar JM, Gerhardt T, Gonzalez A, et al. Mechanisms for episodes of hypoxemia in preterm infants undergoing mechanical ventilation. J Pediatr 1995;127:767-73.

37. Di Fiore JM, Walsh M, Wrage L, et al.; SUPPORT Study Group of Eunice Kennedy Shriver National Institute of Child Health and Human Development Neonatal Research Network. Low oxygen saturation target range is associated with increased incidence of intermittent hypoxemia. J Pediatr 2012;161:1047-52.

38. Pringle KC. Human fetal lung development and related animal models. Clin Obstet Gynecol 1986;29:502-13.

39. Wolfs TG, Jellema RK, Turrisi G, Becucci E, Buonocore G, Kramer BW. Inflammation-induced immune suppression of the fetus: a potential link between chorioamnionitis and postnatal early onset sepsis. J Matern Fetal Neonatal Med 2012;25 Suppl 1:8-11.

40. Jobe AH, Moss TJ, Nitsos I, Ikegami M, Kallapur SG, Newnham JP. Betamethasone for lung maturation: testing dose and formulation in fetal sheep. Am J Obstet Gynecol 2007;197:523.e1-6.

41. Seehase M, Collins JJ, Kuypers E, et al. New surfactant with SP-B and C analogs gives survival benefit after inactivation in preterm lambs. PLoS One 2012;7:e47631.

42. Sweet DG, Carnielli V, Greisen G, et al.; European Association of Perinatal Medicine. European consensus guidelines on the management of neonatal respiratory distress syndrome in preterm infants-2013 update. Neonatology 2013;103:353-68. 